\title{
Launching injury epidemiology
}

\author{
Guohua Li ${ }^{*}$ and Charles J DiMaggio
}

\begin{abstract}
Advances in injury epidemiology and prevention are among the landmark achievements in epidemiology and public health in the past century. Despite remarkable success and growth, the field of injury epidemiology did not have its own publication outlet until now. This commentary marks the debut of the new academic journal Injury Epidemiology and introduces the reader to the first batch of peer-reviewed manuscripts accepted for publication in this new journal.
\end{abstract}

Keywords: Accidents; Epidemiology; Injury; Emergency medical services; Public health; Trauma

Epidemiologic research on injury dates back to the 1930s (Godfrey 1937; Holcomb 1938), and over the past eight decades, injury epidemiology has developed into a well-established academic specialty. Early in 1980, advances in injury epidemiology were voted by members of the Epidemiology Section of the American Public Health Association as one of the 10 landmark achievements in American Epidemiology (Haddon 1980; Kraus 2014). Reductions in injury mortality from motor vehicle crashes and occupational mishaps are recognized as two of the ten great public health achievements of the 20th century and the first decade of the 21st century in the United States (Centers for Disease Control and Prevention 1999; 2011). The past three decades have witnessed a remarkable growth in injury control research, training, and practice, both in scope and in depth. In the United States, the National Center for Injury Prevention and Control became an independent program of the Centers for Disease Control and Prevention in 1997. Since then, many state health departments have established programs for injury prevention activities and over a dozen universities have established injury control research centers. To address the tremendous health burden of injury morbidity and mortality at the global level, the World Health Organization in 2000 established the Department of Injury and Violence Prevention, which has produced a series of influential reports on violence, traffic injury, and childhood injury. Despite the remarkable growth in injury epidemiology, there has been no academic journal dedicated to publishing scholarly work in this scientific disciplineuntil now.

The launch of this new journal represents a milestone in the evolution of injury epidemiology and prevention. In addition to the need for a professional publication outlet, several factors coalesced to give birth to Injury Epidemiology. Among them were the publication of the reference text Injury Research: Theories, Methods, and Approaches (Li and Baker 2012), and the establishment of the Center for Injury Epidemiology and Prevention at Columbia University Medical Center, both in 2012. Through the production of the reference text, we had the opportunity to work with an international group of contributing authors (including some of the most accomplished injury epidemiologists), and one of the largest academic publishing houses in the world. The idea to create a new journal dedicated to the specialty of injury epidemiology grew naturally from the book project, with many of the contributing authors of the reference text serving on the inaugural editorial board (Table 1), and Springer serving as publisher of the new journal. The Center for Injury Epidemiology and Prevention at Columbia University Medical Center is one of the youngest injury control research centers funded by the Centers for Disease Control and Prevention. Establishment of the Columbia Center has provided us with the impetus, enthusiasm, and institutional support necessary for embarking on a sustained academic endeavor.

\footnotetext{
* Correspondence: GL2240@cumc.columbia.edu

Center for Injury Epidemiology and Prevention, Columbia University Medical Center, 622 West 168th St, PH5-505, New York, NY 10032, USA
}

\section{Springer}

(c) 2014 Li and DiMaggio; licensee Springer. This is an Open Access article distributed under the terms of the Creative Commons Attribution License (http://creativecommons.org/licenses/by/2.0), which permits unrestricted use, distribution, and reproduction in any medium, provided the original work is properly cited. 
Table 1 Names and Affiliations of the Inaugural Editorial Board of Injury Epidemiology

\begin{tabular}{ll}
\hline Name & Affiliation \\
\hline Limor Aharonson-Daniel & Ben-Gurion University of the Negev \\
& Be'er Sheva, Israel \\
Jusan P. Baker & Bohns Hopkins University \\
Honorary Editor & Columbia, Maryland, United States \\
Barbara Barlow & New York, New York, United States \\
Honorary Editor & University of British Columbia \\
Peter Barss & Vancouver, British Columbia, Canada \\
Assistant Editor & Johns Hopkins University \\
David Bishai & Baltimore, Maryland, United States \\
Renan Castillo & Johns Hopkins University \\
& Baltimore, Maryland, United States \\
Shane V. Caswell & George Mason University \\
& Fairfax, Virginia, United States \\
Columbia University \\
Magdalena Cerdá & New York, New York, United States \\
Hui Chen & Huazhong University of Science \\
and Technology \\
Wuhan, Hubei, China
\end{tabular}

Li-Hui Chen

David Clark

R. Dawn Comstock

Charles DiMaggio

Associate Editor

Maureen S. Durkin

Caroline F. Finch

Samuel N. Forjuoh

Shannon Frattaroli

Susan G. Gerberich

Assistant Editor

Robyn Gershon

Andrea C. Gielen

Deborah Girasek
Centers for Disease Control and Prevention Hyattsville, Maryland, United States

Maine Medical Center

Portland, Maine, United States

University of Colorado at Denver

Denver, Colorado, United States

Columbia University

New York, New York, United States

University of Wisconsin

Madison, Wisconsin, United States

University of Ballarat

Ballarat, Victoria, Australia

Texas A\&M University

College Station, Texas, United States

Johns Hopkins University

Baltimore, Maryland, United States

University of Minnesota

Minneapolis, Minnesota, United States

University of California, San Francisco

San Francisco, California, United States

Johns Hopkins University

Baltimore, Maryland, United States

Uniformed Services University

of the Health Sciences

Bethesda, Maryland, United States
Table 1 Names and Affiliations of the Inaugural Editorial Board of Injury Epidemiology (Continued)

\begin{tabular}{|c|c|}
\hline \multirow[t]{2}{*}{ Jurek Grabowski } & AAA Foundation for Traffic Safety \\
\hline & $\begin{array}{l}\text { Washington, District of Columbia, } \\
\text { United States }\end{array}$ \\
\hline \multirow[t]{2}{*}{ David Hemenway } & Harvard University \\
\hline & Boston, Massachussetts, United States \\
\hline \multirow[t]{2}{*}{ Delia Hendrie } & Curtin University \\
\hline & Perth, Western Australia, Australia \\
\hline \multirow[t]{2}{*}{ Jamie Hosking } & University of Auckland \\
\hline & Auckland, New Zealand \\
\hline \multirow[t]{2}{*}{ Jonathan Howland } & Boston University \\
\hline & Boston, Massachussetts, United States \\
\hline \multirow[t]{2}{*}{ Paul D. Juarez } & University of Tennessee \\
\hline & Memphis, Tennessee, United States \\
\hline \multirow[t]{2}{*}{ Katherine M. Keyes } & Columbia University \\
\hline & New York, New York, United States \\
\hline Jess Kraus & University of California, Los Angeles \\
\hline Honorary Editor & Los Angeles, California, United States \\
\hline Barbara Lang & Columbia University \\
\hline Managing Editor & New York, New York, United States \\
\hline Jean A. Langlois Orman & US Army Institute of Surgical Research \\
\hline Assistant Editor & Fort Sam Houston, Texas, United States \\
\hline Guohua Li & Columbia University \\
\hline Editor-in-Chief & New York, New York, United States \\
\hline \multirow[t]{2}{*}{ Andrew E. Lincoln } & MedStar Health Research Institute \\
\hline & Hyattsville, Maryland, United States \\
\hline \multirow[t]{2}{*}{ David A. Lombardi } & $\begin{array}{l}\text { Liberty Mutual Research Institute } \\
\text { for Safety }\end{array}$ \\
\hline & Hopkinton, Massachussetts, United States \\
\hline \multirow[t]{2}{*}{ Becky P.Y. Loo } & University of Hong Kong \\
\hline & Pokfulam, Hong Kong, China \\
\hline \multirow[t]{2}{*}{ Francisco J. López-Valdés } & Universidad de Zaragoza \\
\hline & Zaragoza, Spain \\
\hline Stephen W. Marshall & University of North Carolina at Chapel Hill \\
\hline Assistant Editor & Chapel Hill, North Carolina, United States \\
\hline \multirow[t]{2}{*}{ Thelma Mielenz } & Columbia University \\
\hline & New York, New York, United States \\
\hline Matthew Miller & Harvard University \\
\hline Assistant Editor & Boston, Massachussetts, Unites States \\
\hline \multirow[t]{2}{*}{ Lenora Olson } & University of Utah \\
\hline & Salt Lake City, Utah, United States \\
\hline \multirow[t]{2}{*}{ Joyce Pressley } & Columbia University \\
\hline & New York, New York, United States \\
\hline \multirow[t]{2}{*}{ Marizen Ramirez } & University of lowa \\
\hline & lowa City, lowa, United States \\
\hline
\end{tabular}




\begin{tabular}{ll}
$\begin{array}{l}\text { Table } 1 \text { Names and Affiliations of the Inaugural Editorial } \\
\text { Board of Injury Epidemiology (Continued) }\end{array}$ \\
\hline Leon Robertson & Yale University \\
Honorary Editor & New Haven, Connecticut, United States \\
Carol W. Runyan & University of Colorado at Denver \\
& Denver, Colorado, United States \\
Maria Seguí Gómez & University of Navarra \\
& Pamplona, Spain \\
Anbedaw W. Selassie & Medical University of South Carolina \\
& Charleston, South Carolina, United States \\
Dennis F. Shanahan & Injury Analysis, LLC \\
& Carlsdbad, California, United States \\
Gordon Smith & University of Maryland \\
& Baltimore, Maryland, United States \\
Catherine Stayton & New York City Department of \\
Health and Mental Hygiene \\
New York, New York, United States \\
Huiyun Xiang
\end{tabular}

The editorial mission of Injury Epidemiology is to advance the science and practice of injury prevention and control through timely publication and dissemination of peer-reviewed research. An open-access academic journal, Injury Epidemiology aims to be the premier venue for communicating epidemiologic studies of unintentional and intentional injuries, including, but not limited to, morbidity and mortality from motor vehicle crashes, drug overdose/poisoning, falls, drowning, fires/burns, iatrogenic injury, suicide, homicide, assaults, and abuse. Relevant studies are investigations designed to understand the magnitude, distribution, determinants, causes, prevention, diagnosis, treatment, prognosis, and outcomes of injuries in specific population groups, geographic regions, and environmental settings (e.g., home, workplace, transport, recreation, sports, and urban/rural). Of special interest are studies that strengthen the scientific foundation of injury prevention and control and generate objective and practical knowledge to reduce injury morbidity and mortality on a population level. Priority consideration will be given to manuscripts that feature contemporary theories and concepts, innovative methods, and novel techniques as applied to injury surveillance, risk assessment, development of effective interventions, and program/policy evaluation.

The call for submissions was first issued in December 2013. Within three months, we received over 20 manuscripts. The first batch of manuscripts was accepted for publication following rigorous peer-review and revisions, and covers a variety of contemporary topics and innovative methods. Using innovative sampling and recruitment methods and online data collection techniques, Tefft et al. (2014) present survey results that quantify the sizable racial disparities in delayed driving licensure among 18year-olds and that dispel the widely held misconception of graduated driver licensure programs being the main reason for delayed licensure.

Falls have long been recognized as a major cause of disability and mortality in injury epidemiology but did not receive adequate attention from government agencies and healthcare providers until recent years. The study by Stevens et al. (2014) provides valuable data for better understanding the circumstances of falls occurring in residential settings and for designing out the risk in the bathroom for older residents.

Firearm-related injury remains an important and contentious subject in the United States. Although injury researchers have produced compelling epidemiologic evidence that gun ownership is associated with a substantially increased risk of suicide and homicide, there is lingering doubt about the causality of the relationship. In a meticulously performed analysis of national data, Opoliner et al. (2014) show that the strong association between gun ownership and suicide risk is specific to suicide committed by means of firearms and is independent of depression (as indicated by antidepressant prescriptions), thus ruling out one of the putative confounders.

Injuries, both intentional and unintentional, affect American Indians/Alaska Natives (AI/AN) more than any other racial and ethnic groups. The excess risk of injury in AI/ AN represents one of the most pronounced and understudied health disparities. To facilitate injury control research and practice in this underserved population, Sapra et al. (2014) provide a comprehensive review of the epidemiologic literature on interpersonal violence in $\mathrm{AI} / \mathrm{AN}$ by benchmarking the prevalence of child abuse, violence against women, and elder abuse, identifying the risk factors, and outlining the research gaps.

Of special interest are the commentary pieces penned by two pioneers in injury epidemiology and honorary editors of the journal (Baker 2014; Kraus 2014). Professor Baker treats us with several personal stories that illuminate the importance and power of intuitions, first-hand observations, nuances of data, and descriptive epidemiology; and Dr. Kraus reminisces over his outstanding 
career and remarkable journey to injury epidemiology. We hope that our readers find these commentaries insightful and inspiring.

Establishing an academic journal is no small undertaking. If it takes a village to raise a child, it must take an international community to establish an academic journal. We are indebted to Ms. Beryl A. Abrams, Ms. Kathryn Pope, Dr. Margaret Wood, and Dr. Sandro Galea of Columbia University, and Marc Strauss, Hannah Bracken, Jon Gurstelle, and Jerson Baneal of Springer for their assistance and encouragement. Without their support, this journal would not be launched on schedule. Our heartfelt thanks also go to the editorial board members for their service and cooperation, to the reviewers for their expertise and contributions to this labor of love, and to current and prospective authors for their trust and ingenuity. The future of Injury Epidemiology will depend on the editorial board to safeguard its academic integrity and mission, the reviewers to ensure its scientific rigor and quality, and the authors to sustain its vitality and utility.

\section{Competing interests}

The authors have no competing interests to disclose.

Received: 14 February 2014 Accepted: 14 February 2014

Published: 20 March 2014

\section{References}

Baker SP. The stories behind the statistics. Inj Epidemiol. 2014; 1:2.

Centers for Disease Control and Prevention. Ten great public health achievements-United States, 1900-1999. MMWR. 1999; 48(12):241-3.

Centers for Disease Control and Prevention. Ten great public health achievements- United States, 2001-2010. MMWR. 2011; 60(19):619-23.

Godfrey ES. Role of the health department in the prevention of accidents. Am J Public Health Nations Health. 1937; 27(2):152-5.

Haddon W, Jr. Advances in the epidemiology of injuries as a basis for public policy. Public Health Reports. 1980; 95:411-421.

Holcomb RL. Alcohol in relation to traffic accidents. JAMA. 1938; 111(12):1076-85.

Kraus JF. A Journey to and through injury epidemiology. Inj Epidemiol. 2014; 1:3.

Li G, Baker SP. Injury Research: theories, methods, and approaches. New York: Springer; 2012

Opoliner A, Azrael D, Barber C, Fitzmaurice G, Miller M. Explaining geographic patterns of suicide in the US: the role of firearms and antidepressants. Inj Epidemiol. 2014; 1:6.

Sapra KJ, Jubinski SM, Tanaka MF, Gershon RR. Family and partner interpersonal violence among American Indians/Alaska Natives. Inj Epidemiol. 2014; 1:7.

Stevens JA, Mahoney JE, Ehrenreich H. Circumstances and outcomes of falls among high risk community-dwelling older adults. Inj Epidemiol. 2014; 1:5.

Tefft BC, Williams AF, Grabowski JG. Driver licensing and reasons for delaying licensure among young adults 18-20, United States, 2012. Inj Epidemiol. $2014 ; 1: 4$

doi:10.1186/2197-1714-1-1

Cite this article as: Li and DiMaggio: Launching injury epidemiology. Injury Epidemiology 2014 1:1.

\section{Submit your manuscript to a SpringerOpen ${ }^{\circ}$ journal and benefit from:}

- Convenient online submission

- Rigorous peer review

- Immediate publication on acceptance

- Open access: articles freely available online

- High visibility within the field

- Retaining the copyright to your article

Submit your next manuscript at $>$ springeropen.com 